Contrasta la portada llena de color presidida por su estrella, con la contraportada, en la que destacan los trazos negros sobre el blanco del papel, siendo una pequeña intersección azul la única mancha de color que llama nuestra atención y retiene la mirada. Transmite la impresión de ser una conclusión serena de la obra. Este elaborado gran tesoro artístico fue presentado junto con una litografía suelta, cuidadosamente envuelto en papel japonés en una caja lacada, acentuando aún más su sabor japonés ${ }^{33}$.

A través del seguimiento de la correspondencia entre Miró y Takiguchi, se pone de manifiesto que gran parte del valor de estas obras realizadas en colaboración es fruto del enriquecimiento derivado de la interacción cultural. El poeta ejemplifica la admiración japonesa por el mundo del arte contemporáneo en Occidente, y el pintor la aceptación de lo japonés como válido en el camino del arte contemporáneo occidental.

Pilar Cabañas Moreno

\title{
EL ESCULTOR JUAN FERNÁNDEZ Y SU DESCONOCIDA OBRA EN TOLEDO
}

En la Capilla del Sagrario de la Catedral de Toledo, situados a gran altura en unos nichos del muro del mediodía, se sitúan dos grandes esculturas de San Pedro y San Pablo que llaman la atención por su magnífica apostura. Las guías más conocidas que describen la capilla ${ }^{1}$ las identifican como obras en bronce del escultor Juan Fernández.

Parecía extraño que obras de esa envergadura hubieran pasado desapercibidas a los estudiosos de la escultura aunque su dificil accesibilidad lo justificaba. En realidad por lo que podía apreciarse desde abajo y las noticias sobre su material aconsejaron su estudio pausado más teniendo en cuenta que Pompeyo Leoni, el gran maestro de la obra en bronce de los Entierros del Escorial, tuvo un encargo de la catedral de Toledo.

Desmontadas hace poco se supo que las esculturas eran en realidad de madera y que hubo de sanearse la madera atacada por polilla que no había evitado la rica capa de panes de oro que la recubrían ${ }^{2}$. La noticia planteaba el problema de saber cómo se había divulgado el error

formas coloreadas, concluyendo la obra con una gran mancha roja para equilibrar la pesadez visual del texto, contrapunto de aquel círculo rojo pequeño que aparecía al inicio como recuerdo del símbolo de Japón, el sol naciente. Se entiende porqué, aunque sólo fuera por razones ópticas y estéticas, Miró rechazara la idea de incluir prosa en Proverbes à la main. La abundancia de ideogramas emborracha. No es de extrañar que finalmente no se hiciera en otro idioma, ya que hubiera sido una obra totalmente diferente. El hermoso juego entre la verticalidad de las líneas de escritura y la horizontalidad del discurso pictórico, hubiera sido difícil de lograr con el sistema de escritura occidental. La forma de escribir de arriba hacia abajo, y de derecha a izquierda, permite la utilización de un formato que ayuda a leer el discurso escrito y el pictórico de forma continuada, dejándonos avanzar sin llegar al final «de página», hasta que la obra concluye. Ritmo y equilibrio son dos de las características que mejor definen esta obra.

${ }^{33}$ Los poemas recogidos en esta obra son: Joan Miró (1936); En compagnie des étoiles de Miró (1966); Itinéraire (1967) y Raison de rire (1969).

' PARro, Sixto-Ramón, Toledo en la mano o descripción histórico-artística de la magnífica catedral y de los demás célebres monumentos. Toledo, 1857. Edición del Instituto Provincial de Investigaciones y Estudios toledanos, 1978. CEDILLo, Conde de, Catálogo Monumental y Artístico de la Catedral de Toledo. Toledo, 1919. Edición con introducción y notas de Matilde Revuelta. Diputación Provincial de Toledo, 1991. Inventario artístico de Toledo.Tomo II, La Catedral Primada (Vol. I), 1989.

${ }^{2}$ Agradezco la inapreciable ayuda de D. ${ }^{a}$ Matilde Revuelta que me facilitó el informe del restaurador Don Luciano Gutiérrez Gómez confirmando que su madera habia sido atacada por la polilla.También a Don Evencio Cófreces, Deán de la Catedral, su autorización para que se les hicieran fotografías, dificiles de realizar por la altura en la que se encuentran. 
sobre el material en el que estaban conformadas si no había habido sustitución, no detectada en la bibliografía.

Por ello, en breve síntesis que no pretende ser exhaustiva, se recogieron los textos principales que las mencionaban advirtiendo que el primero en el tiempo conocido era la fiable noticia de Pérez Sedano sobre su pago el año de 1614 a Juan Fernández sin especificar su material pero, eso sí, incluida en un párrafo bajo el epígrafe Adornos de bronce pues se recogían los realizados a Bracho por sus labores, especialista en este campo, aunque a continuación se habla de una portada de piedra berroqueña pagada a Juan de Inarra y de la cantidad citada abonada al escultor por el San Pedro y el San Pablo de la Capilla del Sagrario. Ceán Bermúdez recogió la noticia en sus mismos términos ${ }^{3}$.

Una vez conseguidas sus fotografías la buena factura de las esculturas aconsejó detectar la primera mención equivocada sobre su material, por si hubiera habido una sustitución posterior al texto de Pérez Sedano, que se localizó en la obra de Parro . En efecto este autor en su descripción de la Capilla del Sagrario menciona Dos hornacinas en que se representan a San Pedro y San Pablo y son de bronce dorado a fuego de una sola pieza y ejecutadas por el escultor Juan Fernández, autor de la Virgen y de los escudos de piedra que hay sobre la puerta esterior de la sacristía a quien el Cabildo nombro aparejador de sus obras en 1627, cita que por la fecha del texto no parece que autorice a pensar en cambios ${ }^{4}$. Es posible, como se ha dicho, que la mención de Pérez Sedano incluida en el apartado de los Bronces y el difícil acceso a las esculturas equivocaran a Parro y que los estudios posteriores no rectificaran el error por las mismas circunstancias, pero en todo caso y por si acaso se revisó la obra documentada , ya que no estudiada ni apenas identificada, de Juan Fernández, que a juzgar por lo sabido nunca trabajó el bronce siendo sin embargo abundantes sus obras en madera, posiblemente mármol y piedra.

Comprobadas las noticias sabidas sobre este arquitecto y escultor toledano se advirtió que su labor, desarrollada más o menos entre las fechas de 1580 ¿? a la de 1627 , fecha de su nombramiento como Aparejador de las obras de la Catedral de Toledo en el círculo inmediato de Juan Bautista Monegro, es más interesante que lo que anticipan las escuetas noticias sobre sus colaboraciones.

De los datos expurgados sobre su vida parece deducirse que podía ser el cantero que, en El Escorial, posiblemente al frente de una cuadrilla como tantos otros que fueron llamados a distintos lugares de España para colaborar en la gran empresa ${ }^{5}$, se ocupa de sacar piedra para la obra por los años de 1579-1580, en las fechas que Monegro se ocupa de las figuras de los Reyes para la fachada del Monasterio, según noticias que aparecen consecutivas en los datos proporcionados por Gregorio de Andrés ${ }^{6}$, pues además, como se dirá, en la obra de Fernández se perciben claros ciertos influjos de las figuras del gran retablo de los Leoni y de la obra de Monegro en El Escorial.

En todo caso su quehacer, centrado en Toledo donde ya se le menciona el año de 1586, aparece claramente en la órbita de éste último pues ya el año de 1591 se le encomiendan unos

\footnotetext{
${ }^{3}$ Pérez Sedano, Francisco, Datos documentales inéditos para la Historia del Arte español. I. Notas del Archivo de la Catedral de Toledo redactadas sistemáticamente en el siglo xviII por el Canónigo-Obrero ... Madrid, Centro de Estudios Históricos, 1914. Zarzo del Valle, Manuel R., Datos documentales para la Historia del Arte español, II. Documentos de la Catedral de Toledo, colección formada en los años 1869-1874 y donada al Centro en 1914, por ... Madrid, Centro de Estudios Históricos, 1916. Cé́n Bermúdez, Juan Agustín, Diccionario Histórico de los más ilustres Profesores de las Bellas Artes en España.Madrid, 1800.

${ }^{4}$ PARro, cit.

5 Estella, Margarita, «Problemas de la escultura cortesana hacia 1600...», en Real Monasterio-Palacio de El Escorial. Estudios inéditos en el IV Centenario de la terminación de las obras. Madrid, Dept ${ }^{\circ}$ Arte «Diego Velázquez», del CSIC, 1987,221 , nota 1 .

${ }^{6}$ ANDRÉs, Gregorio de, Inventario de documentos sobre la construcción y ornato del Monasterio de El Escorial existentes en el Archivo de su Real Biblioteca. Anejo a Archivo Español de Arte, Madrid, Instituto «Diego Velázquez» del CSIC, 1972.
} 

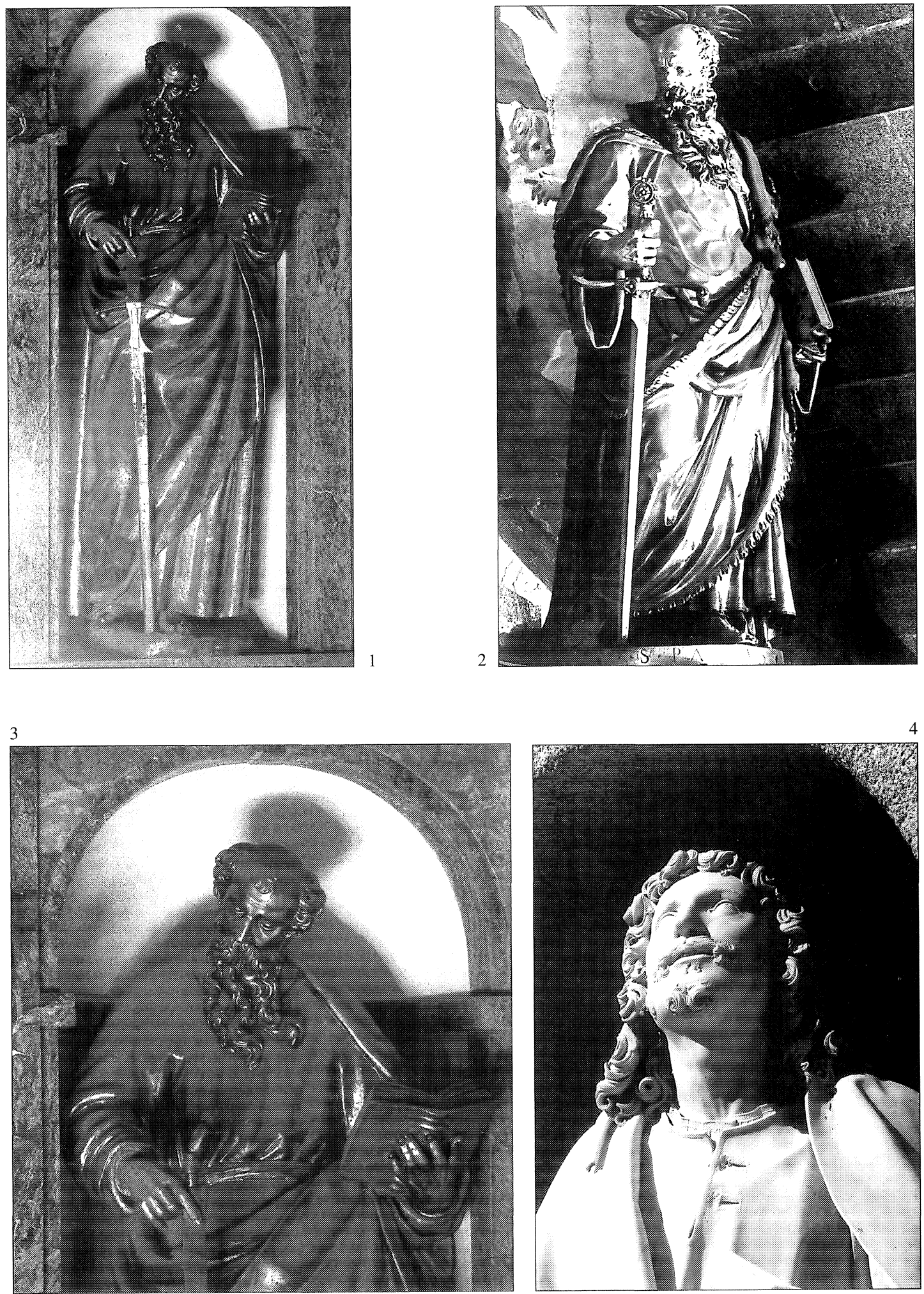

Figs. 1 y 3. Juan Fernández, San Pablo. Toledo, Catedral.

Fig. 2. León y Pompeyo Leone, San Pablo del retablo. El Escorial, Monasterio.

Fig. 4. Juan Bautista Monegro, San Juan. El Escorial, Monasterio. 
capiteles para el Alcázar toledano ${ }^{7}$ que precisamente llevará a cabo junto a Miguel González y el cantero Alonso de Vallejo, sin duda el futuro gran escultor de la escuela cortesana ${ }^{8}$. El año de 1600 Toribio González, de personalidad artística muy afín a la de nuestro escultor, le nombra con otros artistas tasador de su retablo del Convento de los Mínimos de Toledo ${ }^{9}$. Juan Bautista Monegro concierta Compañía el año de 1602 con el alcalaíno Francisco de la Torre, los toledanos Toribio González, Miguel González primo del anterior y Juan Fernández para llevar a cabo la sillería, el retablo mayor y alguna otra obra que le encargan para el Monasterio de la Orden de Santiago en Uclés ${ }^{10}$ y en 1605 dió las trazas para que Juan Fernández contratara el retablo del Hospital de Yepes ${ }^{11}$.

El año de 1607 Monegro se hace cargo de la obra de la Capilla del Sagrario a la muerte de Vergara y a sus órdenes aparece un equipo en el que se integra Juan Fernández y Giraldo de Merlo que pronto, como se verá por las noticias conocidas, se destaca como un experto escultor en el grupo. Precisamente ahora se le encargan a Merlo unos escudos que deberán ser como el de arriba realizado por Juan Fernández que al año siguiente se ocupa de realizar otros escudos de piedra y unas cabezas de piedra blanca, en este caso para la Puerta del Perdón de la catedral. Las noticias se prodigan en estos años y así por las mismas fechas Monegro que se encarga del retablo de la Capilla de los Meneses en Santa Isabel de los Reyes de Toledo, nombra como tasador de su obra a Juan Fernández que actúa de nuevo junto a Toribio González y al pintor Pedro López. También aparece citado Giraldo de Merlo el año de 1609 al que avalan Juan Fernández y el platero Salinas para realizar el retablo de la Ermita del Socorro en Colmenar Viejo. Cuando el 2 de enero de 1609 Merlo presenta fianzas para la realización del retablo de Sigüenza, es avalado entre otros por Juan Fernández ${ }^{12}$.

En la segunda década del siglo la actividad de Juan Fernández se centra en la Catedral de Toledo y más concretamente en la obra de la Capilla del Sagrario. Las noticias de Pérez Sedano documentan un San Andrés tasado por Monegro en 1611, no localizado. En estas fechas Toribio González hace las puertas de nogal de la Capilla pero sus escudos se encargan a Fernández que en la portada de la antesacristía realiza un grupo de la Asunción, con ángeles. El año de 1614 como se ha dicho se le paga la hechura de los Santos Pedro y Pablo y aún en 1617 se ocupa de otros escudos de armas para el patio ${ }^{13}$.

En esta misma fecha el escultor se encarga de otras obras ajenas a las catedralicias y Fernando Marías documentó su retablo para la Ermita de los Dados de Maqueda que lleva a cabo con el pintor Francisco Granello, el hijo del pintor escurialense Niccolo, circunstancia que también apoya la sugerencia de la estancia de Fernández en El Escorial ${ }^{14}$. Los restos del retablo recompuesto se encuentran en la iglesia de Santa María de esta villa y facilitaron nuevos elementos de estudio de su arte.

Precisamente el año de 1622 se emprende otra obra de importancia, el retablo mayor del convento toledano de Santa Clara, contratado en principio por el pintor Diego de Aguilar aun-

\footnotetext{
7 Vid. nota 3: Pérez Sedano y Zarco del Valle. García Rey, Verardo, «Juan Bautista Monegro, escultor y arquitecto», Boletín Sociedad Española Excursiones, 1931, 109, 183; 1932, 22,129, 236; 1933, 148, 204; 1934, $202 ; 1935,53,211$.

${ }^{8}$ Estella, Margarita, «Los Leoni y la escultura cortesanas: Antón de Morales, Alonso Vallejo y Antonio de Riera», en Madrid en el contexto de lo Hispánico desde la época de los Descubrimientos. Dept ${ }^{\circ}$ Historia del Arte II (Moderno). Universidad Complutense de Madrid, 1994, 389-411, p. 401.

9 Marías, Fernando, «Nuevos documentos de pintura toledana de la primera mitad del siglo xviI», Archivo Español de Arte, 1978,409 y ss., p. 412.

${ }^{10}$ Marías, Fernando, La Arquitectura del Renacimiento en Toledo, 1541-1631. II, Madrid, CSIC, 1985.

11 Marías, La Arquitectura, cit.

12 Pérez Sedano, cit. Marías, «Nuevos documentos...», cit. Muñoz Jiménez, J. M., La arquitectura del Manierismo en Guadalajara, p. 254, nota 78.

13 Pérez Sedano, cit.

14 Marías, «Nuevos documentos...», cit.
} 

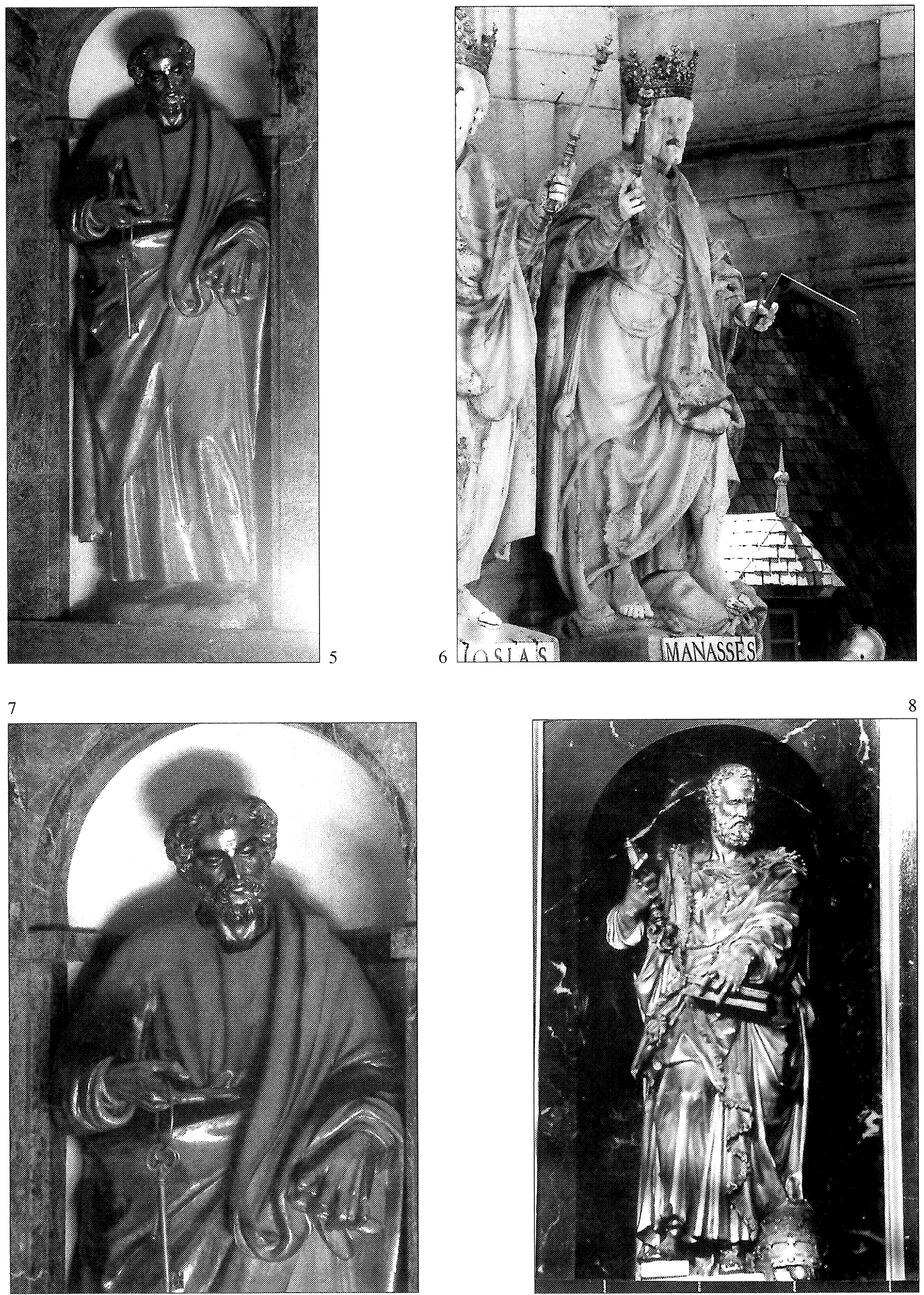

Figs. 5 y 7. Juan Fernández, San Pedro. Toledo, Catedral.

Fig. 6. Juan Bautista Monegro, Manasés. El Escorial, Monasterio.

Fig. 8. Pompeyo Leone, San Pedro de la Custodia. El Escorial, Monasterio 
que parece que sus trazas se deben a Jorge Manuel Theotocopuli. Sus lienzos son de Tristán y sus esculturas , de noble prestancia, se deben a Juan Fernández con el que colabora el ensamblador Mañas ${ }^{15}$. Aunque se conocen otros datos sobre la actividad del escultor, la noticia última de importancia es su nombramiento como Aparejador de las obras de la Catedral en 1627, fecha a partir de la cual no se han localizado otras posiblemente por la avanzada edad del artista pues venía desarrollando su actividad, posiblemente iniciada en El Escorial quizás con unos 20 años, desde más o menos el año de 1580.

El arte de Juan Fernández puede ahora estudiarse no solo a través de sus obras conservadas, suficientes incluso para conocer la evolución de su estilo, sino también a través del entorno artístico en el que se mueve, círculo de gran interés pues de él surgieron dos de los grandes escultores de la escuela cortesana, Alonso Vallejo y Giraldo de Merlo. No se incorpora a ellos Juan Fernández posiblemente por su mayor arraigo en la Ciudad Imperial que reconoce su dedicación con el nombramiento de Aparejador de las obras de su Catedral. Esta circunstancia impidió en cierto modo el progreso de su arte que aquellos vivificaron en contacto con el de la Corte pero no obstante su obra nos lo muestra como un experto conocedor del arte de la talla tanto en piedra como en madera.

Sin duda el mejor exponente de su arte lo constituyen sus esculturas de San Pedro y San Pablo en las que concentró sus habilidades y anteriores conocimientos y en ellas pueden estudiarse las fuentes que le inspiraron. De Monegro repite la elegante apostura de sus Evangelistas de El Escorial como el San Marcos, pero las siluetas de los Santos de Fernández son menos ampulosas y aunque los pliegues blandos de su indumentaria recuerdan a los que aparecen en estas esculturas escurialenses, concretamente la vuelta del manto a la derecha de su San Pedro, se hace más complicada y sabia en la figura del Manasés de Monegro de la fachada del Monasterio. No obstante la composición de estas figuras no se ajusta exactamente a las utilizadas por Monegro y así, por ejemplo, el San Pablo de cabeza ligeramente inclinada a la izquierda con larga barba rizosa que recuerda la factura del cabello del San Juan de Monegro y que influirá asimismo en la técnica de Merlo, repite casi literalmente la del San Pablo que corona el retablo de los Leoni de El Escorial, del que ha tomado prácticamente todos los detalles de la posición de la cabeza en movimiento contrapuesto al de la barba, como indicando un brusco movimiento de aquella, la posición de los brazos etc. Las ilustraciones de ambas esculturas bastan para comprobar estos extremos (figs. 1-4).

El San Pedro también se inspira en la obra de los Leoni pero no tanto en el monumental que hace pareja con el San Pablo en el extremo derecho del retablo escurialense sino más bien en el delicioso San Pedro que se representa en uno de los nichos de la custodia obra de Pompeyo Leoni, según aclara en su correspondencia. El detalle de sujetar el libro con los dedos intercalados señalando página se repite en ambas esculturas pero aunque la cabeza del Santo de Fernández se inspira en la del realizado por Leoni, apenas hay otros recuerdos de su refinado arte en la escultura de la Catedral toledana (figs. 5-8).

El recuerdo de lo escurialense se mantiene en otras obras de Fernández como en su extraño San Jerónimo de Maqueda relacionado en su apostura con el San Marcos o quizás mejor el San Juan del gran retablo pero en todo caso la lección aprendida en esta magna obra aparece matizada por el bronco arte de Monegro del que no obstante no consigue aprender su correc-

\footnotetext{
15 Archivo Histórico Nacional. Sección de Clero. Toledo, Santa Clara, Libro 1576. Cuando se consultó ya se conocían estos datos por Lafuente Ferrari, recogidos por Angulo, Diego y Pérez Sánchez, Alfonso E., Pintura toledana de la primera mitad del siglo XVII. Madrid, Instituto Diego Velázquez del CSIC. Inventario Artístico, cit. MARTínez CAVIRó, Balbina, Conventos de Toledo. Toledo, Castillo Interior. Madrid, Ediciones El Viso, 1990. Localizó también los documentos sobre el retablo en el Archivo del convento y es la que da el nombre de Jorge Manuel como autor de las trazas.
} 

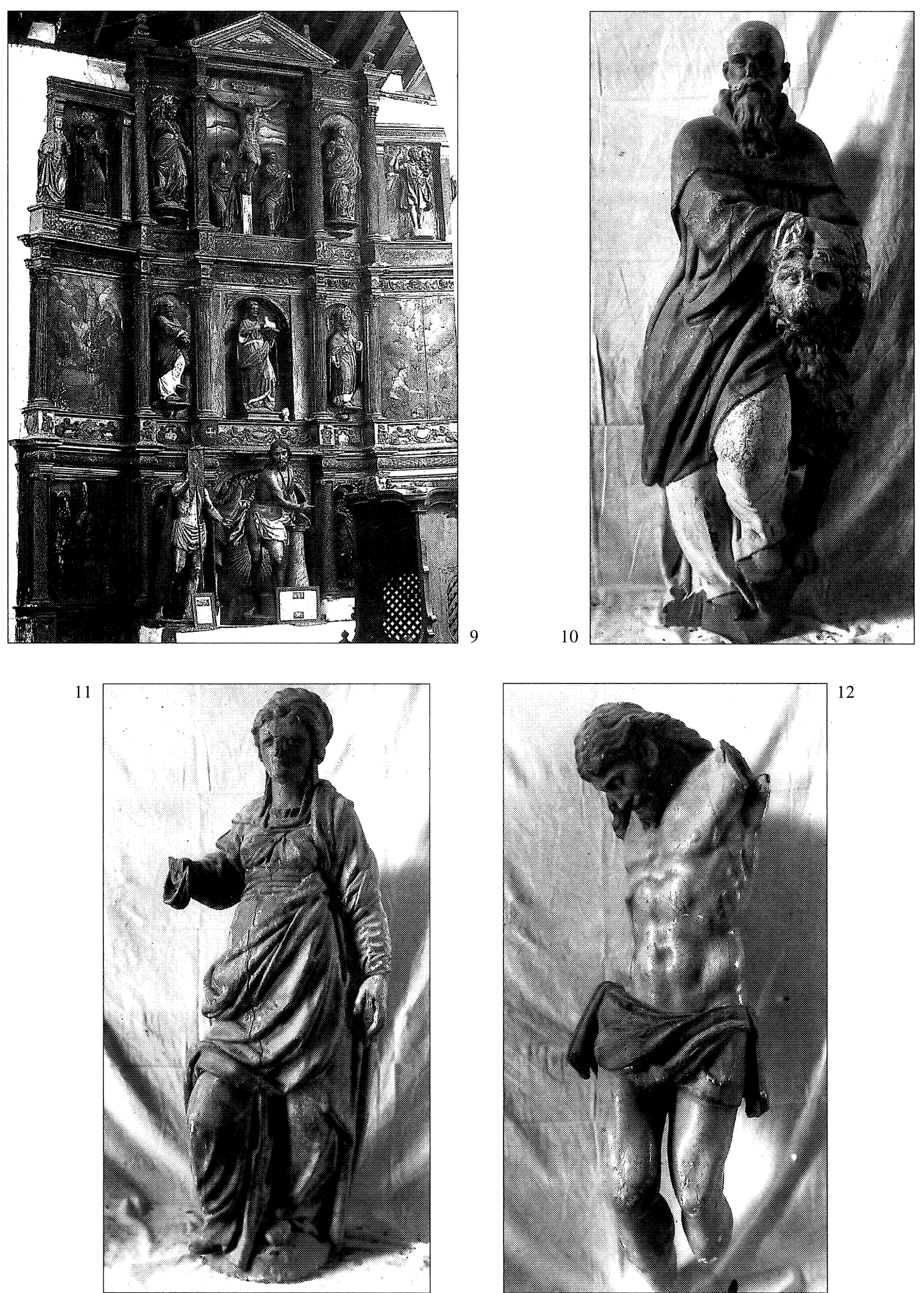

Fig. 9. Francisco Granello y Juan Fernández, Retablo. Maqueda (Toledo), Iglesia de Santa María (procede de la Ermita de Nuestra Señora de los Dados). (Fotografía anterior a 1936).

Figs. 10, 11 y 12. Juan Fernández, San Jerónimo, Santa y Crucificado. 
ción en la talla, su majestuosidad en las aposturas ni la sabiduría de sus composiciones ${ }^{16}$. Las figuras del San Cristóbal y de la Santa de Maqueda ya no responden a esta influencia y han perdido dignidad en el tratamiento de la composición y de la talla. No obstante, el Cristo de su Calvario presenta una bella anatomía y finos rasgos fisionómicos (figs. 9-12).

Aunque la obra de este escultor merece un estudio más detenido de su abundante obra las vistas sirven para apreciar su valía advirtiendo que sin duda por su intensa actividad su arte se degrada al avanzar los años aunque aún luce con maestría en sus tallas del retablo de Santa Clara.

Margarita M. Estella

${ }^{16}$ Estella, Margarita, «Los Leoni, escultores entre Italia y España en Los Leoni (1509-1608). Escultores del Renacimiento italiano al servicio de la Corte de España. Madrid, Museo del Prado, 18 mayo/12 julio 1994, 19-62.- Estella MARCos, Margarita, «El Retablo Mayor de la Basílica» en La escultura en el Monasterio de El Escorial. Actas del Simposium. San Lorenzo del Escorial, 1-4 de septiembre de 1994, 103-139. Vid. también notas 7, 9 y 15. Vicente y GarCía, Asunción «Juan Bautista Monegro y la escultura escurialense» en La escultura en el Monasterio... vid. supra, 189-213. (La autora también publicó una amplia monografía sobre el escultor). 